\title{
Dynamic Linkages between Food Inflation and Its Volatility: Evidence from Sri Lankan Economy
}

\author{
Abdul Majeed MOHAMED MUSTAFA ${ }^{1}$, Selliah SIVARAJASINGHAM ${ }^{2}$
}

Received: July 21, 2019 Revised: September 16, 2019 Accepted: September 24, 2019

\begin{abstract}
This study examines the dynamic linkages between food price inflation and its volatility in the context of Sri Lanka. The empirical evidence derived from the monthly data for the period from 2003M1 to 2017M12 for Sri Lanka. The relationship between inflation rate and inflation volatility has attracted more attention by theoretical and empirical macroeconomists. Empirical studies on the relationship between food inflation and food inflation variability is scarce in the literature. Food price inflation is defined as log difference of food price series. The volatility of a food price inflation is measured by conditional variance generated by the FIGARCH model. Preliminary analysis showed that food inflation is stationary series. Granger causality test reveals that food inflation seems to exert positive impact on inflation variability. We find no evidence for inflation uncertainty affecting food inflation rates. Hence, the findings of the study supports the Friedman-Ball hypothesis in both cases of consumer food price inflation and wholesale food price inflation. This implies that past information on food inflation can help improve the one-step-ahead prediction of food inflation variability but not vice versa. Our results have some important policy implications for the design of monetary policy, food policy thereby promoting macroeconomic stability.
\end{abstract}

Keywords : Food Inflation, Food Price Inflation, Inflation Volatility, Sri Lanka

JEL Classification Code : E31, E51, P22, P44

\section{Introduction}

The knowledge about the linkage between the level of inflation and its associated uncertainty is important for making decision about the priority of either targeting the level of inflation or stabilizing monetary policy in an economy. As the cost of inflation and inflation uncertainty on growth and welfare are significant, it is useful to determine the direction of the causality between inflation

1 First Author and Corresponding Author, Senior Lecturer in Business Economics, Department of Management, Faculty of Management and Commerce, South Eastern University, Sri Lanka. [Postal Address: Dr.A.M.M.Mustafa Department of Management, Faculty of Management and Commerce, South Eastern University, Oluvil, \#32360, Sri Lanka] Email: amustafa@seu.ac.lk

2 Professor in Economics, Department of Economics \& Statistics, Faculty of Arts, University of Peradeniya,

Sri Lanka. Email: ssivaraj@pdn.ac.lk

(c) Copyright: Korean Distribution Science Association (KODISA)

This is an Open Access article distributed under the terms of the Creative Commons Attribution Non-Commercial License (http://Creativecommons.org/licenses/by-nc/4.0/) which permits unrestricted noncommercial use, distribution, and reproduction in any medium, provided the original work is properly cited. and inflation uncertainty. Following Nobel lecture of Friedman (1977), the relationship between inflation rate and inflation uncertainty has attracted more attention by theoretical and empirical macroeconomists. According to Friedman (1977), high inflation will create political pressure to reduce it, but policy makers may fear recessionary effects and be reluctant to lower inflation, resulting in future inflation uncertainty. Friedman (1977) argued that increased variability of inflation distort relative prices and adds an additional risk to long term contracting. In addition, he asserted that high levels of inflation are costly since they raise inflation variability. Hence it leads to inefficient decisions and decreases in economic growth and welfare. Ball (1992) formalizes and supports Friedman's hypothesis in a game theoretical framework. Hence, Friedman and Ball argue that high inflation creates higher inflation uncertainty. In contrast, Cukierman and Meltzer (1986) advocate that inflation uncertainty could lead to inflation and also lower long run economic growth.

Despite the considerable number of empirical research on the relationship between inflation and inflation variability, 
the empirical literature to date has supplied contradictory evidence on the two hypothesis of Friedman (1977) and Cukierman and Meltzer (1986). In addition, the past literature, to our knowledge, shows that there remain scarce in-depth studies focusing on this issue in the context of food price inflation. In addition, the issue remains unexplored in case of Sri Lanka. Most of the studies have focused on the relationship between general inflation and inflation uncertainty in developed countries. However, there are few studies available on the issue for developing/emerging countries. Therefore, this study intends to fill the void in the literature. Hence, this study would contribute significantly to the existing knowledge. This study attempts to answer the following questions: i) are food price inflation and food price inflation volatility stationary series, ii. Is there evidence to support Friedman hypothesis? iii) Is there evidence to support Cukierman and Meltzer (1986) hypothesis?

\section{Food Inflation in Sri Lanka - at Glance}

Food is an important element of cost of living index represented by Colombo Consumer Price Index (CPI) in Sri Lanka. Food prices affect an economy in several ways, such as cost of living, investment, and trade balance. As 80 percent of the households in Sri Lanka spend more than 40 percent of their income on food. Food price dynamics play important role in the economy. As food expenditure accounts for larger proportion of consumer price index in Sri Lanka, food price dynamics play important role in general price in the economy. The impact of food price inflation on general (CPI) inflation is substantially larger in Sri Lanka. The contribution of food inflation to general inflation is 77 percent in December 2017 (Central Bank of Sri Lanka, 2018).

It is also noted that Sri Lanka falls in the higher inflation risk area. Figure 1 shows the impact of rising food prices on CPI inflation in various developed and developing economies. The impact of food price increases on CPI inflation is substantially larger in developing countries than in developed countries. Apparently, Sri Lanka, in particular, is located in the higher inflation risk area.

Food price volatility is one of the major concerns for policy makers and development practitioners worldwide. Inflation volatility/uncertainty is not only distort the decisions regarding future saving and investment due to less predictability of real value of future nominal payments, but also extends the adverse effects of these distortions on the efficiency of resource allocation and the level of real activity (Fischer, 1981; Golob, 1993; Holland, 1993). Volatility of inflation, volatility of food price inflation has negative impacts on different financial, and economic variables, political stability hence eventually deteriorates the economic growth and welfare. Volatility of inflation distorts the decision making regarding future saving and investment, the efficiency of resource allocation and the level of real output (Fischer, 1981; Golob, 1993; Holland, 1993).

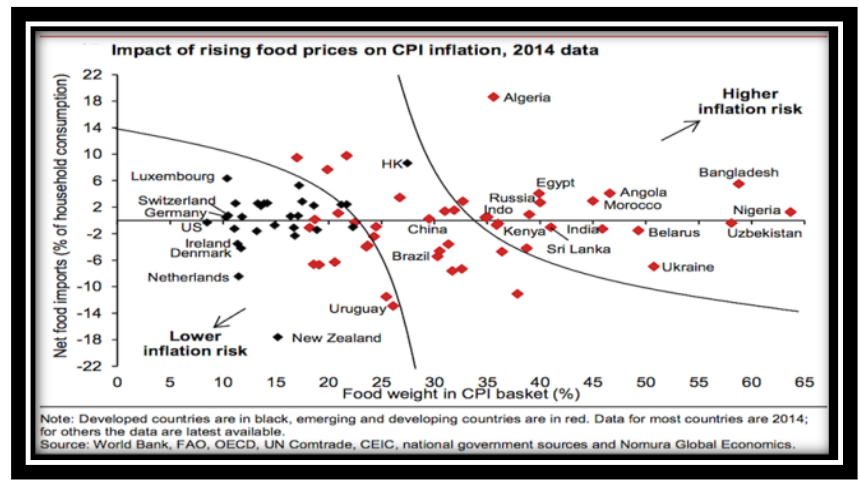

Figure 1: Impact of Rising Food Prices on CPI Inflation, 2014

Understanding the dynamics of food price, its volatility and inflation help in planning policy design and policy responses. The high and volatile food price dynamics pose significant challenges for developing countries including Sri Lanka where households spend a larger share of their income on food.

The contribution of the study is threefold. Firstly, this study examine Friedman-Ball hypothesis, Cukierman and Meltzer's (1986) hypothesis in the case of food inflation though all studies in the literature focused on general inflation. As far as we know, there were no studies on this issue in the case of food price inflation. Secondly, FIGARCH model capture long memory property of volatility series fractionally integrated, $\mathrm{I}(\mathrm{d})$, is considered to derive a proxy for conditional variance series. In most of the studies from developed countries, conditional variance series are derived using GARCH model that does not capture long memory characteristics. Thirdly, this study empirically test the relationship between food inflation and food inflation volatility for Sri Lankan context. There were ample of work on this issue in developed countries. However, there were no studies in the context of Sri Lanka. Thus, the findings of this study can have a number of important policy implications for food production, trade, and monetary policy makers in the case of Sri Lanka. Hence this study will add significantly to available knowledge.

The main objective of the study is to examine Friedman hypothesis in the case of food inflation in Sri Lanka. Friedman's (1977) and Ball's (1992) hypotheses say that higher inflation invokes more inflation uncertainty. In contrast, Cukierman and Meltzer's (1986) hypothesis is that higher inflation uncertainty leads to more inflation. Both these hypotheses are examined using Granger causality tests. The specific objectives are i) to test the stationarity property of the variables of food inflation, food inflation volatility, ii) to test the Friedman hypothesis, iii) to test the CukiermanMeltzer inflation uncertainty hypothesis in the case of food inflation.

The structure of the paper is as follows. Section 2 describes food inflation at glance in Sri Lanka. Section 3 
briefly reviews the literature. Section 4 describes the data and methodology; Section 5 discusses the empirical results. Finally, Section 6 summarizes the main conclusions.

\section{Literature Review}

This section provides theoretical background and empirical review of literature on the inter-relationship between inflation and inflation uncertainty briefly. To the best of our knowledge, there are no literature on the issue in the context of food inflation, we present the theory and review of literature here related to the issue of the relationship between of general inflation and its variability.

\subsection{Theoretical Background: Inflation and Inflation Volatility}

There is a well-known proposition that a rise in inflation increases uncertainty about future inflation. Okun (1971) expressed this proposition in the early 1970s. Friedman postulated that rising inflation brought about by attempts to raise employment, creates pressure to lower inflation and increases private agents' uncertainty about future monetary policy and inflation. Inflation uncertainty reduces the level of investment and economic activity and could be a primary influence of on business cycle (Engle, 2004). In a market economy, inflation uncertainty reduces the price system's efficiency in coordinating economic activity (Wilson, 2006). Friedman states that the more uncertain inflation is to extract the signal about relative prices from the absolute prices. Distorted prices misallocate resources, they lower the level of economic efficiency and the rate of growth, thereby raising the unemployment rate and finally welfare loss. When inflation is engrained in an economic system, it is difficult and costly to lower it because inflationary expectations become inertial and cannot be quickly and easily lowered to a sustainably low level. Ball (1992) puts a case for the argument in a game theoretical framework where asymmetric information holds. According to Friedman and Ball, higher inflation rates generate greater uncertainty about the future policy so about future inflation rates.

\subsection{Empirical Studies}

There are ample empirical studies that examine the relationship between inflation and inflation variability. There exists a positive relationship between inflation and its unpredictability/uncertainty for a given level of investment, (Okun, 1971; Logue \& Willet 1976; Friedman, 1977; Taylor, 1981). They explained intuitively as higher inflation may induce erratic policy response to counter it with consequent unanticipated inflation movements.

Okun (1971) first gave an intuitive explanation for positive correlation between the level and variability of inflation. Okun's argument was based on the non-linearity of the Phillips curve. Positive association between mean and variance of inflation has been extensively documented in the literature; Since the 1970s, academics have started to give more attention to the relation between inflation and its temporal variance. There is ample empirical evidence of this relationship in economic literature. However, the theoretical underpinnings of this area have not been rigorously investigated. Many empirical studies provide evidence of the positive relationship between mean and variance of inflation. For examples, Okun (1971); Logue and Willet (1976); Friedman (1977); Taylor (1981); Evans(1991), Grier and Perry (1998); Nas and Perry (2000); Ball, Cecchetti, and Gordon (1990); Cukierman and Wachtel (1979); Taylor (1981); Golob (1993); and Daal, Naka, and Sanchez (2005) provided evidence in support of the Friedman-Ball hypothesis. In contrast, Cukierman and Meltzer (1986) hypothesis is supported by the findings of Holland (1995) and Baillie, Bollerslev, and Mikkelsen (1996). However, existing literature on this issue has not yet been addressed the relationship in context of food price inflation, in particular in developed or developing countries including Sri Lanka.

\section{Research Methods}

\subsection{Data}

Variables used in the study are Colombo Consumer Price Index for Food and non-Alcoholic Beverages, (CFPI), Wholesale Food Price Index (WFPI), Two food price indices are used in the study. CFPI were collected from the department of census and Statistics, WFP is collected from Central Bank of Sri Lanka. The inflation series of CFPI, WFPI are denoted by INFCFPI, INFWFPI respectively. Data used in the study are monthly data spanning from $2003 \mathrm{M} 1$ to $2017 \mathrm{M} 12$. All the series are transformed into natural logarithms, inflation is defined as log difference of price series, $\quad \pi=100 * \ln \left(P_{t}-\ln P_{t-1}\right) \quad$ where $P$ is price index. Most food price series often admit a non-stationary component, but food price inflation (log difference) seems to be stationary.

The volatility (or Uncertainty) of a food price inflation is measured by various measures, namely standard deviation / variance of the series, absolute food price inflation, squared food price inflation, and conditional variance generated by the FIGARCH model. The absolute food inflation $\left(\left|\pi_{t}\right|\right.$ ), squared food inflation $\left(\pi_{t}^{2}\right)$ and conditional variance of food inflation generated by FIGARCH model are used as proxies for variability of food inflation. Ball (1992), and Cukierman and Meltzer (1986) have used conditional variance of inflation for inflation uncertainty as a proxy variable. 


\subsection{Analytical Tools}

This study uses two approaches to examine the relationship i) graphical method, ii) inferential method. First, we employ scatter plot with confidence ellipse and locally weighted scatter-plot Smoother (LOESS) regression curve line graph. The second method is Granger causality test.

\subsubsection{Unit Root Tests}

Further, the Augmented Dickey Fuller test is carried out, as prerequisite test, to check stationarity property of a variable.

\subsubsection{Granger Causality Test}

Granger causality test is employed to identify the direction of causal relationship between the food price inflation and food inflation variability. Granger causality tests (GCT) are valid for stationary series as standard statistical tests are valid under stationary assumptions. Granger causality from one variable to another means that the conditional forecast for the latter can be significantly improved by adding lagged variables of the former to the information set. Causality is defined as: $X_{t}$ is said not to Granger cause $Y_{t}$ if

$$
E\left(Y_{t+h} \mid J_{t}, X_{t}\right)=E\left(Y_{t+h} \mid J_{t}\right)
$$

Pairwise Granger causality test ( $F$ test) from single equation method, $\mathrm{F}$ test applied to the joint significance of the lags of each explanatory

Considering two series, $X_{t}$ and $Y_{t}$, integrated order one, the $\mathrm{GC}$ test is in the form as:

$$
\Delta X_{t}=\alpha_{1}+\sum_{i=1}^{n 1} \alpha_{11, i} \Delta Y_{t-i}+\sum_{j=1}^{m 1} \alpha_{12, j} \Delta X_{t-j}+u_{X, t}
$$

$$
\Delta Y_{t}=\alpha_{2}+\sum_{i=1}^{n 1} \alpha_{21, i} \Delta X_{t-i}+\sum_{j=1}^{m 1} \alpha_{22, j} \Delta Y_{t-j}+u_{Y, t}
$$

where $u_{x, t}$ and $u_{y, t}$ is stationary random processes intended to capture other pertinent information not contained in lagged values of $X_{t}$ and $Y_{t}$. The lag lengths, $n$, and $m$ are decided by AIC in the study. The series $Y_{t}$ fails to Granger-cause $X_{t}$ if $\alpha_{11}(j)=0\left(j=1,2,3, \ldots m_{1}\right)$; and the series $X_{t}$ fails to Granger-cause $Y_{t}$ if $\alpha_{21}(i)=0(i=1,2$, $\left.3, . . n_{1}\right)$.

\subsection{The Fractional Integrated Conditional Heteroscedasticity Model}

Volatility series typically has a fractional value of $d$. The fractionally integrated GARCH model proposed by Baillie et al. (1996) is denoted by $\operatorname{FIGARCH}(p, d, q)$. FIGARCH model allows accounting for the long memory of volatility within a dynamic framework. The FIGARCH $(1, d, 1)$ model assumes the growth variable (inflation) follows as

$$
\pi_{t}=\sigma_{t} \varepsilon_{t}, \quad \text { where } \quad \sigma_{t}>0 \quad, \quad \varepsilon_{t} \sim \text { i.i.d. }(0,1)
$$

$$
\sigma_{t}^{2}=\omega+\beta \sigma_{t-1}^{2}+\left[1-\beta L-(1-\delta L)(1-L)^{d}\right] \pi_{t}^{2}
$$

FIGARCH process displays short memory for $d=0$. For FIGARCH model, the persistence of a shock at long lags is proportional to $j^{-d-1}$. This FIGARCH model captures long memory in volatility.

\section{Results and Discussions}

\subsection{Descriptive Statistics, Correlation Analysis and Unit Root Tests}

Preliminary analysis shows how food inflation and food inflation volatility interrelated. For this purpose, exploratory data analysis (EDA), unit root test are employed. Figure 1 shows the mean and variance dynamics of food price inflation in Sri Lanka. The mean and standard variance are calculated for each month of the year. This figure reveals that mean and variance of food price inflation move together over time. The standard deviation (SD) of food price inflation exeeds the mean of food price inflation most of the time periods.

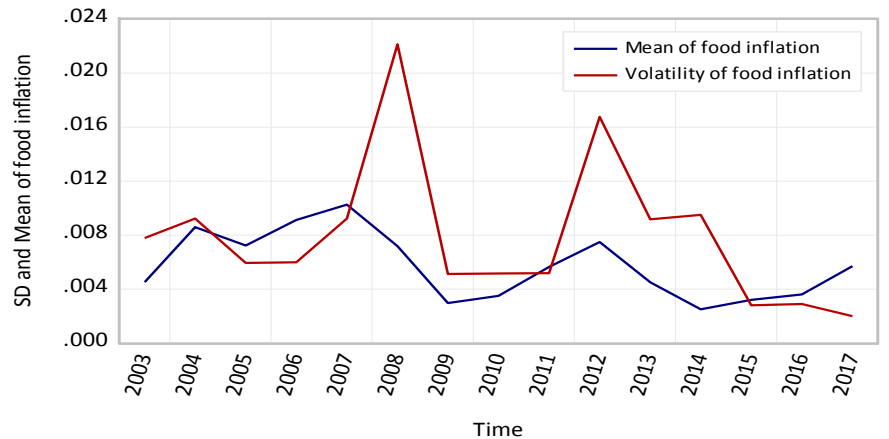

Figure 2: Mean Food Price Inflation and Volatility of Food Price Inflation, 2003M1-2017M12 


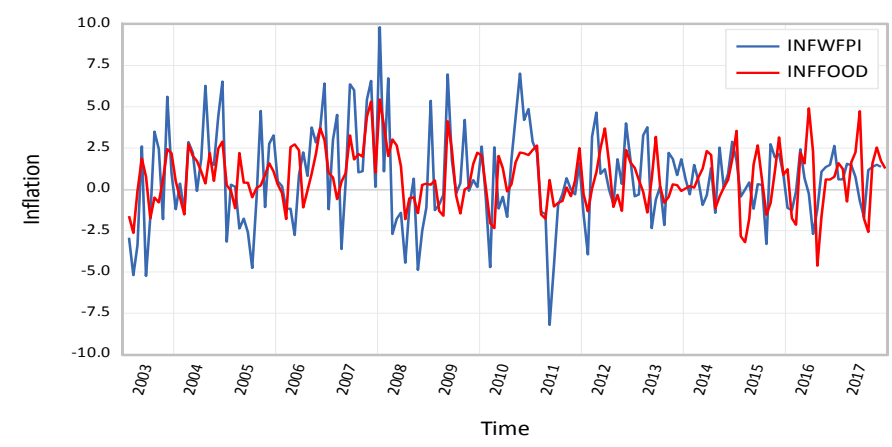

Figure 3: INFWFPI and INFFOOD 2003-2017

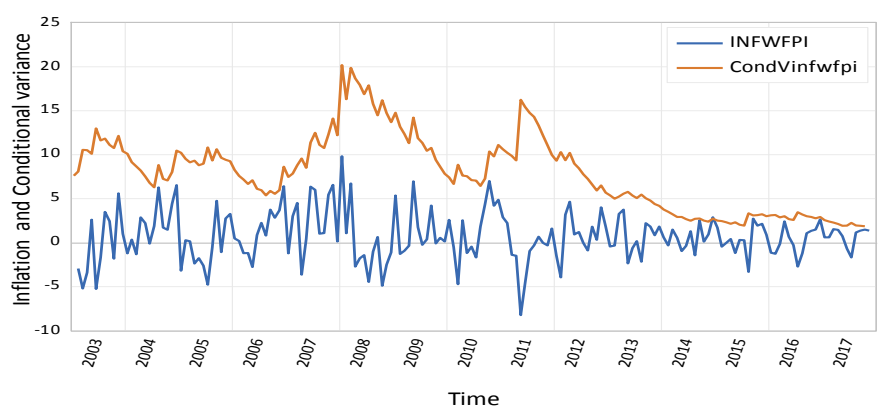

Figure 4: INFWFPI and CVINFWFPI 2003-2017

The volatility measures of absolute inflation, squared inflation and conditional variance of food inflation are compared with food inflation trend. The association is exhibited in the scatter plot with confidence ellipse. They show the positive relationship between food price inflation and variability of the inflation.

Table 1: Unit Root Test Results- Sri Lanka

\begin{tabular}{|l|c|c|c|}
\hline \multirow{2}{*}{ Variables } & $\begin{array}{c}\text { Level } \\
\text { Intercept only }\end{array}$ & $\begin{array}{c}\text { First Difference } \\
\text { Intercept only }\end{array}$ \\
\cline { 2 - 4 } & Test Statistics & Test Statistics & ADF \\
\cline { 2 - 4 } & ADF & $-10.389(0.000)$ & $\mathrm{I}(0)$ \\
\hline INFCFPI & $-9.31(0.000)$ & $-12.323(0.000)$ & $\mathrm{I}(0)$ \\
\hline INFWFPI & $-10.316(0.000)$ & $-11.087(0.000)$ & $\mathrm{I}(0)$ \\
\hline CVINFCFPI & $-3.294(0.016)$ & $-17.178(0.000)$ & $(1)$ \\
\hline CVINFWFPI & $-1.119(0.708)$ & & \\
\hline $\begin{array}{l}\text { Note: at the 5\% significance level, INFCFPI, INFWFPI, CVINFCFPI variables are stationary at level. CVINFWFPI is nonstationary. } \\
\text { unit root test regression model is selected with intercept only } \\
\text { probability values are in parentheses, }(p)\end{array}$
\end{tabular}

\subsection{Causality Relationship between Food Price Inflation and Volatility of Food Price Inflation}

Empirical results of bivariate Granger causality analysis are reported in Table 2. It shows the evidence of causality relationship between food price inflation and food price inflation volatility (conditional variance) series. According to these results, both food inflation series (INFCFPI, INFWFPI) Granger causes its own volatility of inflation

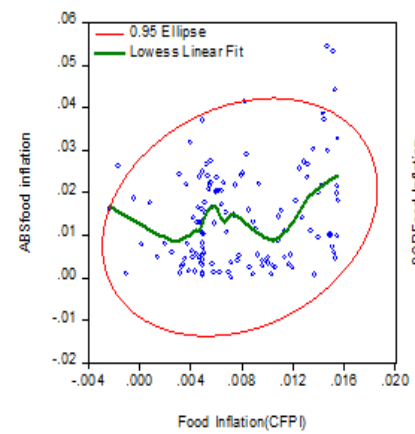

(a)

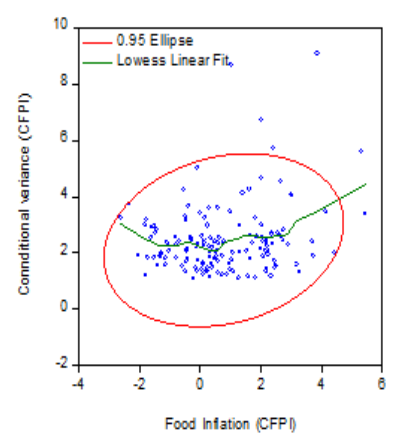

(c)

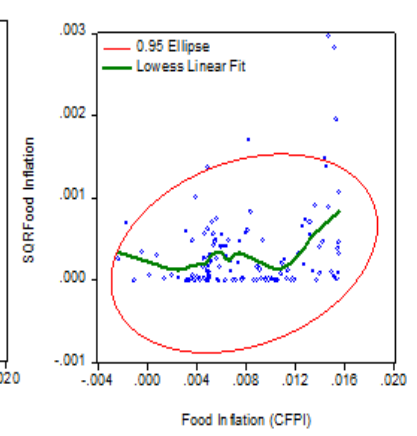

(b)

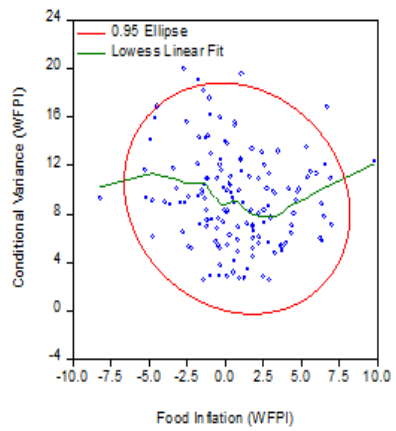

(d)
Figure 5: Food inflation vs Food inflation volatility

The stationarity properties of the inflation and volatility series are examined and presented in Table 1. ADF test shows that food inflation (INFCFPI), wholesale food inflation (INFWFPI) and conditional variance of food inflation are stationary variables. In contrast, conditional variance of wholesale food inflation (CVWFPI) is nonstationary variable and integrated order one. 


\subsubsection{Bivariate Granger Causality Tests}

Table 2: Bivariate Granger Causality Test between food Inflation and food Inflation Volatility

\begin{tabular}{|l|l|l|}
\hline Null Hypothesis & $\boldsymbol{F}$ Statistic & $\boldsymbol{P}$-value \\
\hline INFCFPI does not Granger cause CVINFCFPI & $6.823^{*}$ & 0.001 \\
\hline CVINFCFPI does not Granger cause INFCFPI & 0.035 & 0.965 \\
\hline INFWFPI does not Granger cause DCVINFWFPI & $4.635^{*}$ & 0.011 \\
\hline DCVINFWFPI does not Granger cause INFWFPI & 2.534 & 0.082 \\
\hline
\end{tabular}

Note: CV refers for conditional variance of the food inflation variable, ${ }^{*}$ indicates significance at $5 \%$ level, D refers first difference, INF refers inflation.

Note: conditional variance of WFPI was nonstationary. Thus we used first difference of it. Conditional variance of food inflation was stationary.

However, Cukierman-Meltzer (1986) hypothesis; "inflation uncertainty affects inflation", is not supported by the results of our sample using bivariate Granger causality analysis. In sum, the results are supportive to the FriedmanBall hypotheses. Therefore, the Central Bank of Sri Lanka should try to stabilize the inflation rate in the face of inflationary shocks. The results of the study are consistent with the results of who say that price levels and price volatilities are likely to be positively associated.

\section{Conclusions and Limitation}

This paper has tried to answer three research questions i) are food price inflation and food price inflation volatility stationary series, ii) Is there evidence to support Friedman hypothesis? iii) Is there evidence to support Cukierman and Meltzer (1986) hypothesis? The main objective of the study is to examine the relationship between food inflation and its volatility in Sri Lanka. According to the unit root tests, food inflation, wholesale food inflation and conditional variance of food inflation are found to be stationary series. However, conditional variance of wholesale food inflation is identified as nonstationary series. The Granger causality test showed a strong evidence in line with the Friedman-Ball causal link; inflation causes inflation uncertainty. However, there was no evidence for Cukierman and Meltzer (1986) hypothesis; "inflation uncertainty affects inflation".

This implies the need for better monetary stabilization. Economists find the relationship as a central importance for policy analysis. The findings support the notions that an emerging market economy with low to moderate inflation can experience inflation uncertainty. As food inflation and food inflation volatility are interrelated, both could have a significant impact on general inflation. Thus, the findings could be useful to food policy makers to formulate the stabilization programs and inflation targeting policies. These results may guide policy initiatives for achieving and maintaining price stability. It also support the view of adopting inflation targeting policy in Sri Lanka, to reduce the welfare cost of inflation and its related uncertainties.

It is also worth to note some limitations of the study for future work. Nonlinearity and asymmetric aspects of food price dynamics are not considered in the study. Aggregate food price indices are used in the study for analysis. It would be more informative and useful to use individual food commodities prices. This would help policy planers.

\section{Reference}

Baillie, R. T., Bollerslev, T., \& Mikkelsen, H. O. (1996). Fractionally integrated generalized autoregressive conditional heteroskedasticity. Journal of Econometrics, 74(1), 3-30.

Ball, L. (1992). Why does high inflation raise inflation uncertainty? Journal of Monetary Economics, 29(3), 371-388.

Ball, L., Cecchetti, S. G., \& Gordon, R. J. (1990). Inflation and uncertainty at short and long horizons. Brookings Papers on Economic Activity, 1990(1), 215-254.

Central Bank of Sri Lanka. (2018). Economics and social statistics of Sri Lanka. Colombo, Sri Lanka: Central Bank of Sri Lanka.

Cukierman, A. (1983). Relative price variability and inflation: A survey and further results. In CarnegieRochester Conference Series on Public Policy Vol. 19 (pp.103-157).

Cukierman, A., \& Meltzer, A. H. (1986). A theory of ambiguity, credibility, and inflation under discretion and asymmetric information. Econometrica, 54(5),1099-1128.

Cukierman, A., \& Wachtel, P. (1979). Differential inflationary expectations and the variability of the rate of inflation: Theory and evidence. The American Economic Review, 69(4), 595-609.

Daal, E., Naka, A., \& Sanchez, B. (2005). Re-examining inflation and inflation uncertainty in developed and emerging countries. Economics Letters, 89(2), 180-186.

Khan, S. A. J. S. A. (2010). Inflation and inflation uncertainty: A Garch application-an appraisal from Pakistan. In International Conference on Applied Economics-ICOAE, 345-352.

Evans, M. (1991). Discovering the link between inflation rates and inflation uncertainty. Journal of Money Credit, and Banking, 15, 286-301.

Friedman, M. (1977). Nobel lecture: Inflation and unemployment. Journal of Political Economy, 85, 45172.

Fischer, S., Hall, R. E., \& Taylor, J. B. (1981). Relative 
shocks, relative price variability, and inflation. Brookings Papers on Economic Activity, 1981(2), 381-441.

Golob, J. E. (1993). Inflation, inflation uncertainty, and relative price variability: A survey. (Research Working Paper 93-15). Kansas City, MO: Federal Reserve Bank of Kansas City.

Grier, K. B., \& Perry, M. J. (1998). On inflation and inflation uncertainty in the G7 countries. Journal of International Money and Finance, 17(4), 671-689.

Holland, S. (1995). Inflation and uncertainty: Tests for temporal ordering. Journal of Money Credit and Banking, 27, 827-837.

Holland, A. S. (1993). Uncertain effects of money and the link between the inflation rate and inflation uncertainty. Economic Inquiry, 31(1), 39-51.

Kontonikas, A. (2004). Inflation and inflation uncertainty in the United Kingdom: Evidence from GARCH modelling.
Economic Modelling, 21(3), 525-543.

Logue, D. E., \& Willett, T. D. (1976). A note on the relation between the rate and variability of inflation. Economia, 43(170), 151-158.

Nas, T. F., \& Perry, M. J. (2000). Inflation, inflation uncertainty, and monetary policy in Turkey: 1960-1998. Contemporary Economic Policy, 18(2), 170-180.

Okun, A. M. (1971). The mirage of steady inflation. Brookings Papers on Economic Activity, 2(2), 485-498.

Taylor, J. B. (1981). On the relation between the variability of inflation and the average inflation rate. Paper presented at the Carnegie-Rochester Conference Series on Public Policy. Champaign, IL: University of Illinois.

Wilson, B. K. (2006). The links between inflation, inflation uncertainty and output growth: New time series evidence from Japan. Journal of Macroeconomics, 28(3), 609-620. 